\title{
Emotional context modulates embodied metaphor comprehension
}

\author{
Dalya Samur ${ }^{\mathrm{a}, *}$, Vicky T. Lai ${ }^{\mathrm{b}, \mathrm{c}}$, Peter Hagoort ${ }^{\mathrm{a}, \mathrm{b}}$, Roel M. Willems ${ }^{\mathrm{a}, \mathrm{b}}$ \\ a Donders Institute for Brain, Cognition and Behavior, Radboud University Nijmegen, Kapittelweg 29, 6525 EN Nijmegen, Nijmegen, The Netherlands \\ ${ }^{\mathrm{b}}$ Max Planck Institute for Psycholinguistics, Wundtlaan 1, 6525 XD Nijmegen, Nijmegen, The Netherlands

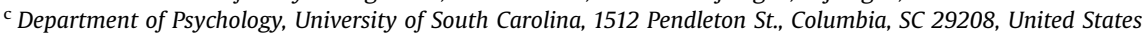

\section{A R T I C L E I N F O}

Article history:

Received 31 May 2015

Received in revised form

29 September 2015

Accepted 2 October 2015

Available online 9 October 2015

Keywords:

Metaphor

Emotion

Discourse comprehension

fMRI

Context

\begin{abstract}
A B S T R A C T
Emotions are often expressed metaphorically, and both emotion and metaphor are ways through which abstract meaning can be grounded in language. Here we investigate specifically whether motion-related verbs when used metaphorically are differentially sensitive to a preceding emotional context, as compared to when they are used in a literal manner. Participants read stories that ended with ambiguous action/motion sentences (e.g., he got it), in which the action/motion could be interpreted metaphorically (he understood the idea) or literally (he caught the ball) depending on the preceding story. Orthogonal to the metaphorical manipulation, the stories were high or low in emotional content. The results showed that emotional context modulated the neural response in visual motion areas to the metaphorical interpretation of the sentences, but not to their literal interpretations. In addition, literal interpretations of the target sentences led to stronger activation in the visual motion areas as compared to metaphorical readings of the sentences. We interpret our results as suggesting that emotional context specifically modulates mental simulation during metaphor processing.
\end{abstract}

(c) 2015 Elsevier Ltd. All rights reserved.

\section{Introduction}

It has long been recognized that experiencing emotions is much more direct than talking about them. Indeed, despite the immediate and concrete experience of emotion, describing feelings in words tends to be via non-literal language (Edwards, 1999; Fainsilber and Ortony, 1987; Lubart and Getz, 1997). For instance, when people describe resentment, they prefer metaphorical expressions, such as 'a storm was brewing inside', over more literal depictions (Fainsilber and Ortony, 1987). Metaphors provide a way to describe what we find hard to express in words (such as emotions), by relating to concrete experiences in the world (Lakoff and Johnson, 2008). That is, concrete experiences in the world, such as pushing an object aside, are used in a metaphorical sense when someone says that he 'pushed his sorrows away'.

Here we investigate specifically whether motion-related verbs when used metaphorically are differentially sensitive to a preceding emotional context, as compared to when they are used in a literal manner. We exploit the past findings that language that describes action or motion ('to throw', 'to write') activates parts of the brain also involved in actual action execution and motion perception (Hauk et al., 2004; Tettamanti et al., 2005; Willems and Casasanto, 2011; Willems et al., 2010a, 2010b). Such findings are

\footnotetext{
* Corresponding author.

E-mail address: Dalyasamur@gmail.com (D. Samur).
}

often taken as evidence for the embodiment of word meaning (Barsalou, 2008). While that interpretation is debated (Mahon and Caramazza, 2008; Willems and Casasanto, 2011; Willems and Francken, 2012; Wilson and Golonka, 2013), there is evidence that sensori-motor regions of the brain can be involved in coding word meaning.

Whether the metaphorical use of motion/action verbs similarly leads to activations of sensori-motor region has been investigated in several neuroimaging studies, with mixed results (Desai et al., 2013; Romero Lauro et al., 2013). In an elegant design, Saygin et al. (2009) compared activation in areas involved in motion detection in the inferior temporal cortex (human area MT, hMT), in response to literal motion sentences (The deer jumped over the brook), figurative/fictive motion sentences (The bridge jumped over the brook), and static control sentences (The deer slept next to the brook). Both fictive and literal motion sentences led to higher activation levels than the static control sentences in the hMT. This suggests that motion semantics is in use when we read about motion in a fictive manner (Boulenger et al., 2009; Desai et al., 2013). Contrary to this is the finding by Raposo et al. (2009), who measured the activation of motor and premotor cortices with three action verb conditions. Isolated action verbs (kick) and sentences with literal use of action verbs (kick the ball) activated the premotor cortex, while sentences with idiomatic use of action verbs (kick the bucket) did not (see also Aziz-Zadeh et al. (2006)). There is no consensus yet concerning the inconsistency in the abovementioned findings. Possible explaining factors include 
novelty (Cardillo et al., 2012; Lai et al., 2015) and context (Schuil et al., 2013). Cardillo et al. (2012) directed attention to novelty as a factor through investigating the shift from novel to conventionalized metaphors and how the brain is tuned to this process. Schuil et al. (2013) showed that sentential context modulates the degree to which motor regions are activated. Hence, the novelty of the figurative language and the context in which it is presented in can have an influence on the level of sensori-motor activations. Overall these studies inform us that early visual and motor regions can be involved in the processing of sentences that describe action in a metaphorical manner.

We hypothesize that the involvement of sensori-motor cortex will be increased when the metaphorical use of motion/action verbs is emotionally loaded. A couple of fMRI studies have examined the link between metaphor and emotion (Bohrn et al., 2012; Citron and Goldberg, 2014). One example is an fMRI study by Citron and Goldberg (2014) in which participants read sentences with metaphorical content ('She looked at him sweetly') and carefully matched literal counterparts ('She looked at him kindly'). Based on an increased activation level to metaphorical as compared to literal sentences in the left amygdala, a structure known to be involved in the processing of emotions and emotional language, the authors concluded that metaphorical statements are more emotionally engaging than literal counterparts. The link between sensori-motor simulation and emotion in metaphorical language is suggestive. Some evidence that sensori-motor simulation could be increased specifically for emotional metaphors comes from a recent rating study. Citron et al. (2015) had participants rate German idioms on a number of psycholinguistic variables including concreteness, defined as the extent to which the figurative meaning could be experienced with one or more sensory modalities. They found a positive relationship between the emotional arousal of the idioms and the rated concreteness. That is, the more the figurative meaning of an idiom could be related to one of the senses, the higher it scored on emotional arousal. This is in line with previous work showing that abstract emotional words are rated higher on imageability compared to concrete emotional words (Altarriba and Bauer, 2004) and that response times to valence decisions are influenced by how much a word is related to a sensory modality (Jacobs et al., 2015).

The current study investigated the role of emotion in the literal and metaphorical interpretations of action/motion phrases. Participants read target sentences preceded by related short stories in four different versions/conditions while being scanned. The target sentences contained action/motion phrases that depending on the preceding stories could be interpreted as literal or metaphorical. Also depending on the preceding stories, the target sentences could be interpreted as high or low on emotion. Having the same target sentences across conditions ensured that any observed differences would be due to the experimental manipulation, and not due to differences in the materials between conditions. Focused region of interest analyses were carried out for regions previously implicated in comprehending motion- and action-related language (Willems and Casasanto, 2011): the primary motor and premotor cortex and the bilateral human motion area hMT. Two separate localizer scans were collected in order to localize these regions.

Our main hypothesis was that sensori-motor activations in reaction to the metaphorical action language would be influenced by emotional context more than literal language. We expect an emotional 'boost' in the embodiment of metaphorical language, which would be expressed in an increased reliance on sensorimotor regions (Citron et al., 2015; Jacobs et al., 2015). Alternatively, there may be a main effect of emotional context, in the absence of an interaction effect. This would mean that emotional context 'boosts' sensori-motor simulation of action language overall, which is a viable alternative given the modulatory function of emotion on a range of cognitive processes, including language comprehension (Chwilla et al., 2011; Kaltwasser et al., 2013; Van Berkum et al., 2013).

\section{Methods}

\subsection{Participants}

25 healthy native Dutch speakers participated for course credit or payment. None of them had neurological problems by self-report; all had normal or corrected-to-normal vision and all were right-handed. Five subjects were removed from the final analysis because of excessive motion artifacts ( 4 participants) and the below chance score on the catch trials ( 1 participant). Data from the remaining 20 participants ( 4 male, mean age $=21.89$, range $18-27$ years) were entered in the analysis. The local ethics committee approved the study (CMO Arnhem-Nijmegen, The Netherlands, protocol number 2001/095) and all participants gave informed consent in accordance with the declaration of Helsinki.

\subsection{Stimuli}

The final stimulus set after norming tests consisted of 120 quadruplets, that is, 120 target sentences preceded by 4 different short stories in Dutch (Table 1). Each target sentence contained the targeted action or motion verbs, such as verbs that imply physical action involving, or leading to movement (e.g., to pick) and those that denote motion (e.g., to fall). Pretests were carried out to ensure that each target sentence in isolation is not metaphorical or literal, and also not highly emotional or arousing (see Pretest 1 and 2 below).

Each story consisted of 3 sentences: The first sentence introduced the setting and the characters involved. The second and third sentences were manipulated according to two experimental factors: Figurativity (Literal, Metaphor) and Emotional Context (Low emotional, High emotional). The manipulation changes the interpretation of the fourth sentence, namely the target sentence, such that this sentence can be interpreted metaphorically with high emotional level, metaphorically with low emotional level, literally with high emotional level, and literally with low

Table 1

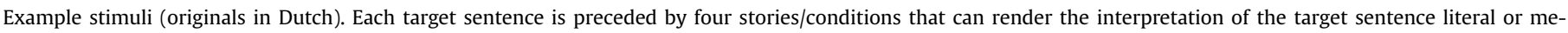
taphorical (Figurativity), and low or high in emotions (Emotional Context). See text for pretest results.

\begin{tabular}{|c|c|c|}
\hline Condition & Context & Target sentence \\
\hline Literal and Low-Emotional Context & Robert was lost in thought. He had his textbook lying open for three hours. He did not want to look at it. & \multirow[t]{4}{*}{ He pushed it away. } \\
\hline Literal and High-Emotional Context & $\begin{array}{l}\text { Robert was lost in thought. He failed to understand the examination material. Angrily, he looked at the } \\
\text { boring book. }\end{array}$ & \\
\hline Figurative and Low-Emotional Context & Robert was lost in thought. He had to make a decision about his job. He did not think about it too much. & \\
\hline Figurative and High-Emotional Context & $\begin{array}{l}\text { Robert was lost in thought. He had to make a decision about his relationship. Thinking about it made him } \\
\text { feel bad. }\end{array}$ & \\
\hline
\end{tabular}


emotional level. The use of action and/or motion words in the story was avoided. The average length of stories (number of words) was matched between conditions $(F<1, p=.82)$.

Additional 24 quadruplets and yes-no comprehension questions about them were created for catch trials, to ensure that participants attended the stimuli. These questions were designed to be not too challenging. For example, if the story started with 'Martin was in a car...', the catch question would for instance be 'Was Martin in a house?'.

Two pretests were carried out on an initial 147 quadruplets to verify our manipulations. In the first pretest, the target sentences were presented without their preceding stories. This pretest served to ensure that the target sentences did not have a bias to be read as metaphorical or literal in isolation, as well as to ensure that target sentences were not highly emotional or arousing when presented on their own. In the second pretest, the target sentences were presented with their preceding stories. This pretest served to ensure that the target sentences were understood as literal or metaphorical and were understood as low or high emotional depending on the preceding context.

In Pretest 1, twelve subjects who did not participate in the second pretest or in the fMRI session rated the 147 target sentences in isolation on a 9 -point scale for valence $(1=$ negative, $9=$ positive) and arousal level ( $1=$ calm, 9=excited) (Lai et al., 2012). Overall, the target sentences had a mean value of 4.78 ( $s$. $d .=1.45$ ) for the valence ratings and a mean value of 5.70 ( $s$. $d .=0.77$ ) for the arousal ratings, indicating that the target sentences when presented outside of a context had no strong valence or arousal associated with them. After completion of the first part, participants were also asked to rate the figurativity of the target sentences (randomized) on a 1-9 scale ( 1 =literal, $9=$ figurative). The mean figurativity rating of the target sentences was 5.62 ( $\mathrm{s}$. $d .=1.32$ ), which is neither very figurative nor very literal. No items were excluded based on the aforementioned scores.

In Pretest 2, twenty-four subjects who did not participate in pretest 1 or in the fMRI session rated the 147 target sentences with their story contexts. Each of the 147 target sentences was paired with one of the four story contexts / conditions and the paired items were rotated via Latin Square rotation, resulting in 4 lists. Each subject was presented with one of the lists, with the items randomized within that list. The subject number and list number were counterbalanced.

The participants were asked whether they would interpret the target sentences as literal or figurative given the story context on a 9 -point scale $(1=$ literal, $9=$ figurative). Based on the ratings, 27 stimuli with mean ratings between 4 and 6 were excluded because the target sentences were not made more literal or more figurative given the story context. Within the finalized experimental 120 stimulus sets, the mean figurativity ratings were $1.98,(s . d .=1.64)$ for the literal condition and $8.01(s . d .=1.59)$ for the metaphorical condition. The figurativity ratings were assessed statistically in repeated-measures ANOVA of 2 Figurativity (metaphorical, litera1) $\times 2$ Emotional Context (high, low). There was a main effect of Figurativity $(F(1,23)=792.97, p<.001)$, which verified our contextual manipulation. There was no main effect of Emotional Context $(F(1,23)=1.76, p=.19)$, or a Figurativity $\times$ Emotional Context interaction effect $(F(1,23)=2.48, p=.13)$, as expected.

As in Pretest 1 , after completion of the first part, the participants rated the valence and the arousal of the target sentences in their story contexts. The valence ratings were presented with 9 -point scale ( $1=$ negative, $9=$ positive). Among the 120 stories, 92 were negative and 28 of them were positive. The valence rating results showed that for the target sentences in the negative stories, the target sentences were rated significantly more negative in the high Emotional Context (mean=3.02) than in the low Emotional Context $($ mean $=4.70)(F(1,23)=104.95, p<.001)$. There was a main effect of Figurativity $(F(1,23)=220.21, p<.001)$ as well as a Figurativity $\times$ Emotional Context interaction $(F(1,23)=50.59$, $p<.001)$. For the target sentences in the positive stories, the target sentences were rated more positive in the high emotional context $($ mean $=7.35)$ than in the low emotional context (mean $=6.56)(F$ $(1,23)=71.15, p<.001)$. There was a main effect of Figurativity $(F$ $(1,23)=14.90, p<.001)$, but no Figurativity $\times$ Emotional Context interaction effect $(F<1, p=.53)$. The arousal ratings results showed that the target sentences were rated significantly lower in arousal in the low emotional context (mean=4.96) than in the high emotional context (mean $=5.87)(F(1,23)=51.01, p<.001)$. There was no main effect of Figurativity $(F<1, p=.87)$. Additionally there was no Figurativity $\times$ Emotional Context interaction $(F(1,23)=3.16, p=.09)$.

\subsection{Task and procedure}

In the fMRI experiment, each participant saw one list with 144 items, of which 24 were catch trials. Each trial started with a fixation cross for $1 \mathrm{~s}$, one of the four versions of a story for $7.5 \mathrm{~s}$, a blank screen of $2 \mathrm{~s}$, followed by the target sentence for $2.5 \mathrm{~s}$. The interval between the story and target sentence was randomly jittered between $1.5-2.5 \mathrm{~s}($ mean $=2 \mathrm{~s}$ ). See Fig. 1 for an example trial.

In the 24 catch trials, participants responded to a question after the target sentence. The questions were about general content of the stories, and the participants responded 'Yes' or 'No' by pressing response buttons with the right or left index finger. The order of response keys was counterbalanced across participants. The questions stayed on the screen until the response occurred or until 5 seconds elapsed. Inter-trial-interval (ITI) was randomly jittered between $3-4 \mathrm{~s}$ (mean=3.5 s).

To define regions of interest in cortical motor and motionsensitive areas, we used two separate localizers. The motor cortex localizer consisted of 18 blocks of $10 \mathrm{~s}$ each in which participants moved their hand, feet, or performed no movement (rest). The instructions were presented visually. The participants were instructed about exemplary movements before entering the scanner; for foot actions they were instructed to move their foot up and down, for hand-related action words they were instructed to open and close their hands continuously. To localize motion sensitive areas in visual cortex, participants watched $10 \mathrm{~s}$ blocks of white dots on a black background that were either moving or stable or they viewed a black screen (rest). The main task comprised around $40 \mathrm{~min}$, and was followed by a $10 \mathrm{~min}$ anatomical scan and the two localizer tasks which took 4 and 3 min, resulting in a total scanning time of $57 \mathrm{~min}$.

\section{4. fMRI recording and processing}

Data were collected on a $1.5 \mathrm{~T}$ Siemens whole body scanner,

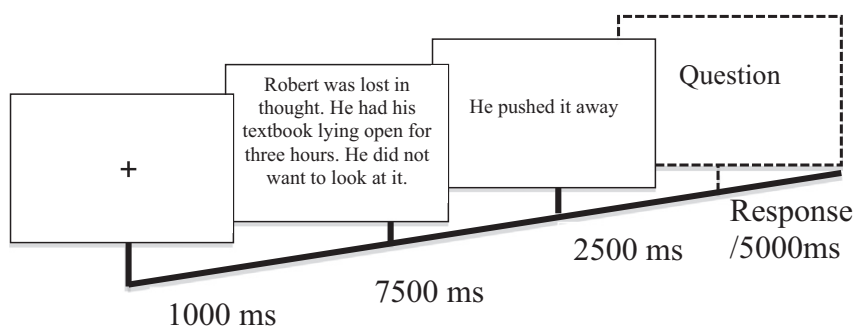

Fig. 1. Design of the experiment. Each trial started with presentation of a fixation cross, followed by the story context, and the target sentence. There was a blank screen in between the story and the target sentence (mean duration 2000 milliseconds), which is not presented here for illustration purposes. In catch trials $(20 \%$ of all trials), a comprehension question was presented at the end of a trial. 
using an eight-channel head coil. Echo-Planar Images (EPI) sensitive to the Blood Oxygen Level Dependent (BOLD) contrast were acquired, covering the whole brain. These functional scans were acquired using the following parameters: repetition time (TR) $2340 \mathrm{~ms}$, echo time (TE) $35 \mathrm{~ms}, 32$ transversal slices, flip angle (FA) $90^{\circ}$, voxel size $3.125 \times 3.125 \times 3.5 \mathrm{~mm}^{3}$ and $0.35 \mathrm{~mm}$ gap between slices. To synchronize the experiment and the scanner acquisition, the scanner triggered the computer running Presentation software (Version 16.2, Neurobehavioral Systems, Inc.).

fMRI data were preprocessed and analyzed using SPM8 (http:// www.fil.ion.ucl.ac.uk/spm/). The first 4 volumes of each session were removed to allow for T1 equilibration. To correct for small head movements, motion correction was applied by aligning all images to the first image in a run. Slice timing correction was performed to correct for delays in slice acquisition. After this step, the T1 image and the EPI images were co-registered to apply them in the same space and data were spatially normalized into Montreal Neurological Institute (MNI) space. Finally, spatial smoothing was applied with a Gaussian smoothing kernel with $8 \mathrm{~mm}$ fullwidth at half maximum.

Statistical analysis was done in the context of the General Linear Model (GLM). For the main task, the instructions, stories, target sentences, catch stories and catch target sentences were modeled separately and the resulting regression model was convolved with a canonical hemodynamic response function (HRF). The estimated parameters of the motion correction algorithm were included in the model as nuisance regressors. Contrast images for each of the four conditions were analyzed in an ANOVA with factors Emotional context (low, high) and Figurativity (literal, figurative). Since results are computed for each voxel separately, there is a substantial multiple comparisons problem, which was taken care of by thresholding statistical images at $p<.001$ at the voxel level, and subsequently defining a cluster level extent using the theory of Gaussian Random Fields, to arrive at a threshold at a $p$-value $<.05$, corrected for the number of comparisons (Poline et al., 1997).

Statistical analysis of the action and motion localizers consisted of constructing a model of all blocks of activation for each condition separately (Hands, Feet, Rest for the action localizer; Motion, No Motion, and Rest for the visual motion localizer). Group analysis consisted of defining areas of interest by comparing Hand $>$ Feet and Feet $>$ Hand for the action localizer and Motion $>$ No Motion for the motion localizer. ROIs were defined by thresholding the group maps at $p<.05$ Family Wise Error corrected (action localizer), or by combining a $p<.001$ threshold at the voxel level with a cluster extent threshold to arrive at a corrected $p<.05$ level (motion localizer). The peak coordinates for the ROIs are as follows: Hand $>$ Feet (left hemisphere: $x=-40$, $y=-28, z=57$; right hemisphere: $x=39, y=-25, z=58$ ). Foot areas (Feet $>$ Hand) were found to be in more ventral areas (because the left and right foot areas are very close to each other we report one peak voxel: $x=-1, y=-35, z=70$ ). Visual motion areas were defined by contrasting Motion $>$ No Motion (left hMT: $x=-44, y=-74, z=-4$; right hMT: $x=46, y=-60, z=6$ ), and location of area hMT is in accordance with previous literature (Dumoulin et al., 2000).

Because our stimulus materials were not preselected to describe motion with the hand or feet specifically, we additionally tested for effects in anatomically defined regions of interest in the cortical motor system. We investigated responses in bilateral primary motor cortex (BA4), and premotor cortex (BA6), defined by means of cytoarchitectonic probability maps (Eickhoff et al., 2005). We choose for this additional testing of the motor and premotor cortex to strike the right balance between the advantages and disadvantages of functionally and anatomically defined ROIs. Our functional ROIs were sample-specific (an advantage), but restricted to Hand and Foot regions (a disadvantage). The anatomical ROIs covered the whole motor cortex (an advantage over the functional ROIs), but were not specific to our sample, and comprised rather large part of cortex, which makes it harder to find specific effects due the averaging over a large number of voxels (both disadvantages). Because of the previously observed hemispheric differences in sensitivity to metaphor, we tested for differences between the left and right hemisphere ROIs by adding the factor Laterality (left, right) to the ANOVA.

\section{Results}

\subsection{Behavioral results}

The participants answered most of the questions for the catch trials accurately (mean $=81 \%$, range $71-92$ ), which indicates that participants were attending to the stimuli. There was no effect of list on the accuracy level $(F<1)$.

\section{2. fMRI results}

\subsubsection{Regions of interest analysis}

For each of the ROIs reported below, the mean activation levels (beta weights) for the target sentences in 4 conditions were entered in a repeated-measures ANOVA with factors Figurativity (metaphorical, literal), Emotional Context (high emotional, low emotional), and Laterality (left, right).

3.2.1.1. Visual Motion areas hMT. In the visual motion ROIs, as defined by the Motion $>$ No-motion contrast from the localizer, there was a Figurativity $\times$ Emotional Context $\times$ Laterality interaction $(F$ $(1,19)=5.27, p<.05$; see Fig. 2$)$, a Figurativity $\times$ Emotional Context interaction $(F(1,19)=5.32, p<.05)$, and a main effect of Figurativity $(F(1,19)=5.37, p<.05)$. None of the other effects yielded significant results: Laterality $(F<1, p=.45)$, Emotional Context $(F$ $(1,19)=2.39, p=.14)$, Laterality $\times$ Figurativity $(F<1, p=.51)$, Laterality $\times$ Emotional Context $(F<1, p=.52)$.

Because of the three-way interaction, we investigated differences for each hemisphere separately. In the right hMT, there was a significant Figurativity $\times$ Emotional Context interaction $(F(1$, $19)=11.67, p<.005$; see Fig. 2), as well as main effects of Figurativity $(F(1,19)=6.15, p<.05)$ and Emotional Context $(F(1,19)=$ $5.41, p<.05)$. Pairwise comparisons showed that the emotional context mattered in metaphors, such that the high-emotion metaphors led to more activation than the low-emotion metaphors $(t$ $(19)=3.79, p<.001)$. This is not the case for the literal interpretations of the target sentences (Literal Low Emotional Context versus Literal High Emotional Context: $|t|<1, p=.32$ ). For the left hMT there was no significant effect (interaction and main effect of Emotional Context: $F<1$, main effect of Figurativity: $(F(1,19)=$ $2.74, p=.11)$.

3.2.1.2. Motor areas. In the motor ROI of the hand area, there was a Figurativity $\times$ Laterality interaction $(F(1,19)=5.24, p<.05)$. None of the other effects yield significant results: Laterality $(F<1$, $p=.71)$, Figurativity $(F<1, p=.67)$, Emotional Context $(F<1$, $p=.42)$, Laterality $\times$ Emotional Context $(F(1,19)=1.24, p=.28)$, Figurativity $\times$ Emotional Context $(F(1,19)=1.61, p=.22)$, Figurativity $\times$ Emotional Context $\times$ Laterality interaction $(F<1, p=.73)$. Similarly, for the ROI of the foot area, there were no significant main effects for Figurativity $(F(1,19)=2.13, p=.16)$, or Emotional Context $(F<1, p=.77)$, nor a Figurativity $\times$ Emotional Context interaction effect, $(F<1, p=.38)$.

In the ROI of the primary motor area (BA4), there was a Figurativity $\times$ Emotional Context interaction $(F(1,19)=4.53, p<.05)$. 
Left hMT

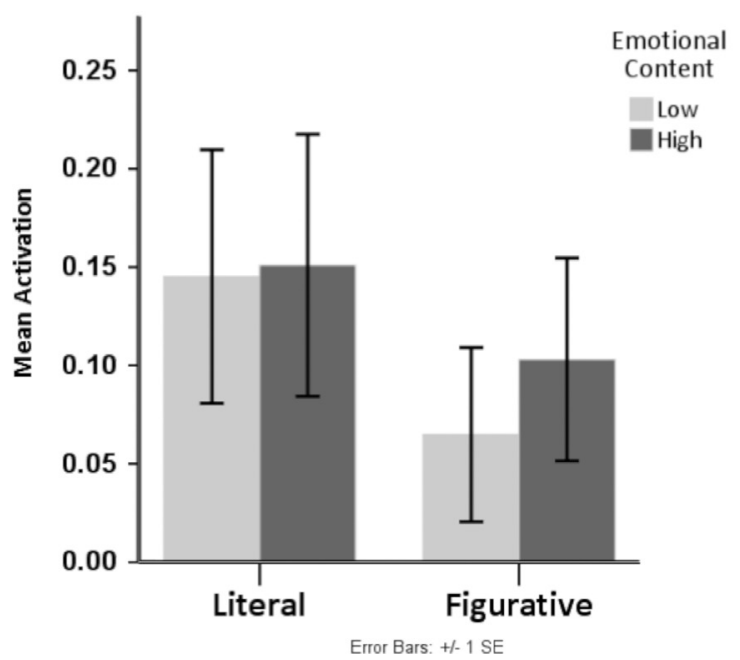

Right hMT

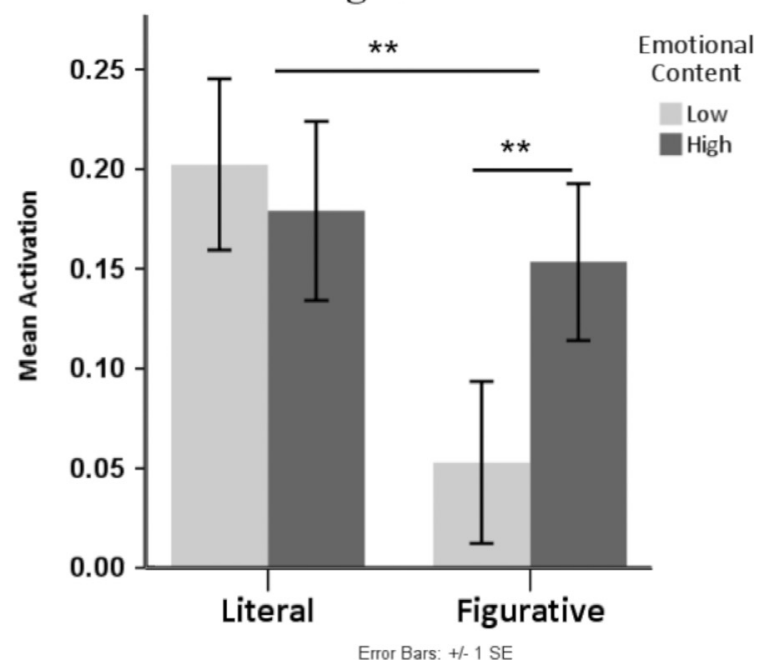

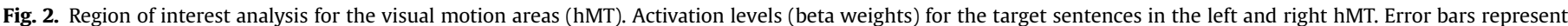
Standard Error of the Mean (SEM). The asterisks $\left(^{* *}\right)$ represent $p<.001$.

None of the other effects yielded significant results: Laterality $(F<1, p=.40)$, Figurativity $(F<1, p=.55)$, Emotional Context $(F<1$, $p=.39)$, Laterality $\times$ Figurativity $(F<1, p=.59)$, Laterality $\times$ Emotional Context $(F<1, \quad p=.94)$, a Figurativity $\times$ Emotional Context $\times$ Laterality interaction $(F<1, p=.88)$.

In BA6 there was a Figurativity $\times$ Laterality interaction $(F(1$, $19)=7.43, p<.05)$. None of the other effects yield significant results: Laterality $(F(1,19)=2.49, p=.13)$, Figurativity $(F<1, p=.35)$, Emotional Context $(F<1, p=.68)$, Laterality $\times$ Emotional Context $(F<1, p=.58)$, Figurativity $\times$ Emotional Context $(F<1, p=.35)$, Figurativity $\times$ Emotional Context $\times$ Laterality interaction $(F<1$, $p=.52)$.

\subsubsection{Whole brain analysis}

To test for areas additionally involved beyond the hypothesized regions of interest, we conducted a whole brain analysis. Left middle temporal gyrus, left middle occipital gyrus and left superior frontal gyrus (see Table 2 and Fig. 3) were more strongly activated for the figurative conditions compared to the literal conditions. We did not find regions that responded to the main effect of Emotional Context nor to the interaction of Figurativity $\times$ Emotional Context.

\section{Discussion}

We investigated whether emotional context differentially influences literal motion language and metaphorical motion language, as reflected by neural activation in sensori-motor areas. The same target sentences were preceded by stories in four versions/ conditions: literal and high emotional, metaphorical and high

Table 2

Results of the whole brain analysis. No activations were observed for the opposite contrast (Literal > Figurative), or for main effects of Emotional Context, or a Figurativity $\times$ Emotional context interaction. All activations are corrected for multiple comparisons at the $p<.05$ level.

\begin{tabular}{ll}
\hline MNI & Label \\
\hline Figurative $>$ Literal & \\
$-50-60-4$ & Left Middle Temporal Gyrus \\
$-40-7824$ & Left Middle Occipital Gyrus \\
-18262 & Left Superior Frontal Gyrus \\
\hline
\end{tabular}

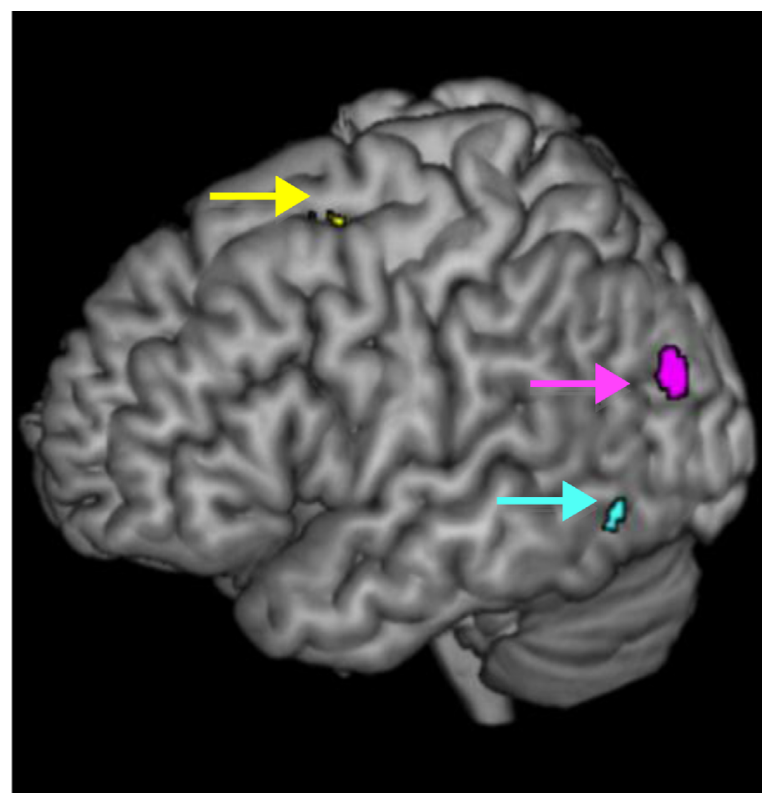

Fig. 3. Whole brain analysis for the figurative $>$ literal contrast. All significant activations ( $p<.05$ corrected) are in the left hemisphere: the middle occipital gyrus (pink), the middle temporal gyrus (cyan), and the superior frontal gyrus (yellow). (For interpretation of the references to color in this figure legend, the reader is referred to the web version of this article.)

emotional, literal and low emotional, and metaphorical and low emotional. We found that the right human MT, an independently localized cortical area sensitive to visual motion, showed more activation for high than for low emotional conditions, but only in the case of metaphorical motion. In literal motion, similar activation levels were found between high and low emotional conditions, and both were more strongly activated than metaphorical motion. The novel finding of our study was the activation in visual motion area getting modulated by the emotional context during the processing of metaphorical sentences. Sensory simulation gets a boost from emotionality in a figurative context, but not in a literal context. We also found that activation of motion areas is stronger for literal motion than for non-literal motion sentences, as is in line with previous research (Saygin et al., 2009).

We interpret the effects found in visual motion areas as simulation of the motion semantics conveyed by our target sentences. 
Sensory simulation gets a boost from emotionality in a figurative context, but not in a literal context, comparable with past rating results (Citron et al., 2015; Jacobs et al., 2015). This suggests that the emotional context leads to a more concrete - more 'embodied' - representation of the metaphorical motion, as compared to the same metaphorical motion occurring in a non-emotional context. Because metaphorical meaning is both concrete and abstract (Forgács et al., 2015), it is possible that the emotional context allows more grounding of the concrete aspect of the metaphorical meaning, as reflected by the similar activation levels between the high emotional metaphor condition and the literal condition (Fig. 2). Alternatively, it may be that the abstract aspect of the metaphorical meaning becomes more grounded, as it has been suggested that emotion constitutes the experiential information that allows grounding of abstract concepts (Kousta et al., 2011). Yet another possibility is that emotionality does not directly influence the content of language (i.e., the abstract or concrete aspects of meaning), but the way in which individual language components are processed and combined (Lai et al., 2015). In this case, the differential modulations of emotion on metaphorical and literal motion may result from differences between metaphor and literal language processing, such as more comparison processes for metaphorical language than literal language (Lai and Curran, 2013). The exact mechanism of how emotion tweaks metaphorical language comprehension remains to be investigated.

The influence of emotional context on metaphorical language processing in hMT was most pronounced in the right hemisphere, evidenced by a three-way Figurativity $\times$ Emotional context $\times$ Laterality interaction. A generally higher sensitivity to figurative language for the right hemisphere has been observed before (Mashal et al., 2015; Lai et al., 2015). Saygin et al. (2009) also reported higher activation in the right hemisphere for fictive motion sentences, as compared to static sentences.

By showing sensitivity to emotional context, our study adds to a growing body of literature showing that sensori-motor cortex activation in response to motion/action language is context-dependent. Some previous studies have failed to find sensori-motor cortex involvement during the understanding of action-related language (Postle et al., 2008) or have shown that motor cortex involvement during the comprehension of action verbs depends on task (Desai et al., 2013; Papeo et al., 2009; Sato, 2008). While a lot of discussion has centered around the question whether sensori-motor cortices are important for semantic representations or not, a more fruitful approach seems to be to ask under which circumstances sensori-motor areas play a role in language understanding (Papeo et al., 2009; van Dam et al., 2012; Willems and Casasanto, 2011; Willems and Francken, 2012). The present study adds to this by showing the specific role that emotional context plays in grounding of metaphorical language.

The observed effects could be due to explicit imagery of the information contained in the target sentences. While we cannot exclude this alternative hypothesis based on the present data alone, we have reason to believe that the simulation interpretation is the more likely one. In previous research, we specifically disentangled the neural representations of sensori-motor activation in response to the reading of action verbs, versus the activation elicited by explicit imagery of the same action verbs (Willems et al., 2010a, 2010b). The main finding of those papers was that reading of action verbs leads to activation in the motor cortex, but this activation is non-overlapping with activations evoked by motor imagery. Moreover, others have argued that the speed with which sensori-motor regions are activated when reading visual or motor-related language is incompatible with an explanation in terms of imagery (Hauk et al., 2006; Moseley et al., 2013), which is a cognitively effortful and slow process (Kosslyn et al., 2001).

Emotional Context also interacted with Figurativity in the primary motor cortex (BA4), which is interpretable in a similar manner giving the sensitivity of motor cortex to motion- and action-related language. Still, we want to raise caution concerning the primary motor cortex finding given that the same result was not observed in the parts of the motor cortex as defined by the action localizer. Also, the interaction effect was not present in premotor cortex (BA6), which is more often implicated in the understanding of action language as compared to primary motor cortex (Kemmerer and Gonzalez-Castillo, 2010; Willems and Casasanto, 2011; Willems et al., 2010b).

The results from the region of interest analysis were not present in the whole brain analysis. This is likely due to the decreased sensitivity of whole brain analysis as compared to region of interest analysis given the substantial multiple comparisons problem which has to be corrected for in the whole brain analysis. Also, it should be noted that any sensori-motor activations in the test of a main effect of Figurativity could be obscured by the numerous other cognitive processes at play during sentence comprehension in context. We defined regions of interest a priori on the basis of separate functional localizer data, leading to an increased sensitivity to detect effects (Saxe et al., 2006). The whole brain analysis showed more activation for metaphorical than for literal language in the left middle temporal gyrus, left middle occipital gyrus and left superior frontal gyrus, which is consistent with the previous literature (Benedek et al., 2014; Lai et al., 2015).

In sum, we provide neural evidence for a tight relationship between emotional and metaphorical language. Activation of visual motion areas in response to metaphorical expressions referring to motion is increased when this expression is embedded within an emotional context, as compared to a non-emotional context.

\section{Acknowledgments}

We thank the research assistants of the Max Planck Institute for Psycholinguistics for help in constructing the stimuli and Prof. Gerard Steen for his feedback on the experimental design at an earlier stage of the study. Dalya Samur was supported by the Huygens Scholarship Program by the Dutch Ministry for Education, Culture and Science, The Netherlands.

\section{References}

Altarriba, J., Bauer, L.M., 2004. The distinctiveness of emotion concepts: a comparison between emotion, abstract, and concrete words. Am. J. Psychol. 117 (3), 389-410. http://dx.doi.org/10.2307/4149007.

Aziz-Zadeh, L., Wilson, S.M., Rizzolatti, G., Iacoboni, M., 2006. Congruent embodied representations for visually presented actions and linguistic phrases describing actions. Curr. Biol. 16 (18), 1818-1823. http://dx.doi.org/10.1016/j. cub.2006.07.060

Barsalou, L.W., 2008. Grounded cognition. Annu. Rev. Psychol. 59, 617-645. http: //dx.doi.org/10.1146/annurev.psych.59.103006.093639.

Benedek, M., Beaty, R., Jauk, E., Koschutnig, K., Fink, A., Silvia, P.J., Neubauer, A.C., 2014. Creating metaphors: the neural basis of figurative language production. Neuroimage 90 (100), 99-106. http://dx.doi.org/10.1016/j. neuroimage.2013.12.046.

Bohrn, I.C., Altmann, U., Jacobs, A.M., 2012. Looking at the brains behind figurative language-a quantitative meta-analysis of neuroimaging studies on metaphor, idiom, and irony processing. Neuropsychologia 50 (11), 2669-2683. http://dx. doi.org/10.1016/j.neuropsychologia.2012.07.021.

Boulenger, V., Hauk, O., Pulvermüller, F., 2009. Grasping ideas with the motor system: semantic somatotopy in idiom comprehension. Cereb. Cortex 19 (8), 1905-1914. http://dx.doi.org/10.1093/cercor/bhn217.

Cardillo, E.R., Watson, C.E., Schmidt, G.L., Kranjec, A., Chatterjee, A., 2012. From novel to familiar: tuning the brain for metaphors. Neurolmage 59 (4), 3212-3221. http:/dx doi.org/101016/j.neuroimage 201111.079.

Chwilla, D.J., Virgillito, D., Vissers, C.T.W.M., 2011. The relationship of language and emotion: N400 support for an embodied view of language comprehension. J. Cogn. Neurosci. 23 (9), 2400-2414. http://dx.doi.org/10.1162/jocn.2010.21578.

Citron, F.M.M., Cacciari, C., Kucharski, M., Beck, L., Conrad, M., Jacobs, A.M., 2015. 
When emotions are expressed figuratively: Psycholinguistic and Affective Norms of 619 Idioms for German (PANIG). Behav. Res. Methods, 1-21. http://dx. doi.org/10.3758/s13428-015-0581-4.

Citron, F.M.M., Goldberg, A.E., 2014. Metaphorical sentences are more emotionally engaging than their literal counterparts. J. Cogn. Neurosci. 26 (11), 2585-2595. http://dx.doi.org/10.1162/jocn_a_00654.

Desai, R.H., Conant, L.L., Binder, J.R., Park, H., Seidenberg, M.S., 2013. A piece of the action: modulation of sensory-motor regions by action idioms and metaphors. NeuroImage 83, 862-869. http://dx.doi.org/10.1016/j.neuroimage.2013.07.044.

Dumoulin, S.O., Bittar, R.G., Kabani, N.J., Baker Jr, C.L., Le Goualher, G., Bruce Pike, G. Evans, A.C., 2000. A new anatomical landmark for reliable identification of human area V5/MT: a quantitative analysis of sulcal patterning. Cereb. Cortex 10 (5), 454-463.

Edwards, D., 1999. Emotion Discourse. Cult. Psychol. 5 (3), 271-291. http://dx.doi. org/10.1177/1354067X9953001.

Eickhoff, S.B., Stephan, K.E., Mohlberg, H., Grefkes, C., Fink, G.R., Amunts, K., Zilles, K., 2005. A new SPM toolbox for combining probabilistic cytoarchitectonic maps and functional imaging data. NeuroImage 25 (4), 1325-1335. http://dx. doi.org/10.1016/j.neuroimage.2004.12.034.

Fainsilber, L., Ortony, A., 1987. Metaphorical uses of language in the expression of emotions. Metaphor Symb. Act. 2 (4), 239-250. http://dx.doi.org/10.1207/ s15327868ms0204_2.

Forgács, B., Bardolph, M.D., Amsel, B.D., DeLong, K.A., Kutas, M., 2015. Metaphors are physical and abstract: ERPs to metaphorically modified nouns resemble ERPs to abstract language. Front. Hum. Neurosci. 9, 28. http://dx.doi.org/ 10.3389/fnhum.2015.00028.

Hauk, O., Johnsrude, I., Pulvermüller, F., 2004. Somatotopic representation of action words in human motor and premotor cortex. Neuron 41 (2), 301-307. http://dx. doi.org/10.1016/S0896-6273(03)00838-9.

Hauk, O., Shtyroy, Y., Pulvermüller, F., 2006. The sound of actions as reflected by mismatch negativity: rapid activation of cortical sensory-motor networks by sounds associated with finger and tongue movements. Eur. J. Neurosci. 23 (3), $811-821$.

Jacobs, A.M., Võ, M.L.-H., Briesemeister, B.B., Conrad, M., Hofmann, M.J., Kuchinke, L., Braun, M., 2015. 10 years of BAWLing into affective and aesthetic processes in reading: what are the echoes? Lang. Sci. 6, 714. http://dx.doi.org/10.3389/ fpsyg.2015.00714.

Kaltwasser, L., Ries, S., Sommer, W., Knight, R.T., Willems, R.M., 2013. Independence of valence and reward in emotional word processing: electrophysiological evidence. Front. Psychol. 4, 168. http://dx.doi.org/10.3389/fpsyg.2013.00168.

Kemmerer, D., Gonzalez-Castillo, J., 2010. The two-level theory of verb meaning: an approach to integrating the semantics of action with the mirror neuron system. Brain Lang. 112 (1), 54-76. http://dx.doi.org/10.1016/j.bandl.2008.09.010.

Kosslyn, S.M., Ganis, G., Thompson, W.L., 2001. Neural foundations of imagery. Nat Rev. Neurosci. 2 (9), 635-642. http://dx.doi.org/10.1038/35090055.

Kousta, S.-T., Vigliocco, G., Vinson, D.P., Andrews, M., Del Campo, E., 2011. The representation of abstract words: why emotion matters. J. Exp. Psychol. Gen. 140 (1), 14-34. http://dx.doi.org/10.1037/a0021446.

Lai, V.T., Hagoort, P., Casasanto, D., 2012. Affective primacy vs. cognitive primacy: dissolving the debate. Front. Psychol. 3. http://dx.doi.org/10.3389/ fpsyg.2012.00243.

Lai, V.T., Curran, T., 2013. ERP evidence for conceptual mappings and comparison processes during the comprehension of conventional and novel metaphors. Brain Lang. 127 (3), 484-496. http://dx.doi.org/10.1016/j.bandl.2013.09.010.

Lai, V.T., van Dam, W., Conant, L.L., Binder, J.R., Desai, R.H., 2015. Familiarity differentially affects right hemisphere contributions to processing metaphors and literals. Front. Hum. Neurosci. 9, 44. http://dx.doi.org/10.3389/ fnhum.2015.00044.

Lai, V.T., Willems, R.M., Hagoort, P., 2015. Feel between the lines: implied emotion in sentence comprehension. J. Cogn. Neurosci. 27 (8), 1528-1541. http://dx.doi. org/10.1162/jocn_a_00798.

Lakoff, G., Johnson, M., 2008. Metaphors We Live By. University of Chicago Press, USA.

Lubart, T.I., Getz, I., 1997. Emotion, metaphor, and the creative process. Creativity Res. J. 10 (4), 285-301. http://dx.doi.org/10.1207/s15326934crj1004_1.
Mahon, B.Z., Caramazza, A., 2008. A critical look at the embodied cognition hypothesis and a new proposal for grounding conceptual content. J. Physiol.-Paris 102 (1-3), 59-70. http://dx.doi.org/10.1016/j.jphysparis.2008.03.004.

Mashal, N., Borodkin, K., Maliniak, O., Faust, M., 2015. Hemispheric involvement in native and non-native comprehension of conventional metaphors. J. Neurolinguist. 35, 96-108.

Moseley, R.L., Pulvermüller, F., Shtyrov, Y., 2013. Sensorimotor semantics on the spot: brain activity dissociates between conceptual categories within $150 \mathrm{~ms}$. Sci. Rep. 3, 1928. http://dx.doi.org/10.1038/srep01928.

Papeo, L., Vallesi, A., Isaja, A., Rumiati, R.I., 2009. Effects of TMS on different stages of motor and non-motor verb processing in the primary motor cortex. PLoS One 4 (2), e4508. http://dx.doi.org/10.1371/journal.pone.0004508.

Poline, J.-B., Worsley, K.J., Evans, A.C., Friston, K.J., 1997. Combining spatial extent and peak intensity to test for activations in functional imaging. Neurolmage 5 (2), 83-96. http://dx.doi.org/10.1006/nimg.1996.0248.

Postle, N., McMahon, K.L., Ashton, R., Meredith, M., de Zubicaray, G.I., 2008. Action word meaning representations in cytoarchitectonically defined primary and premotor cortices. NeuroImage 43 (3), 634-644. http://dx.doi.org/10.1016/j. neuroimage.2008.08.006.

Raposo, A., Moss, H.E., Stamatakis, E.A., Tyler, L.K., 2009. Modulation of motor and premotor cortices by actions, action words and action sentences. Neuropsychologia 47 (2), 388-396. http://dx.doi.org/10.1016/j. neuropsychologia.2008.09.017.

Romero Lauro, L.J., Mattavelli, G., Papagno, C., Tettamanti, M., 2013. She runs, the road runs, my mind runs, bad blood runs between us: literal and figurative motion verbs: an fMRI study. NeuroImage 83, 361-371. http://dx.doi.org/ 10.1016/j.neuroimage.2013.06.050

Sato, A., 2008. Action observation modulates auditory perception of the consequence of others' actions. Conscious. Cogn. 17 (4), 1219-1227. http://dx.doi. org/10.1016/j.concog.2008.01.003.

Saxe, R., Brett, M., Kanwisher, N., 2006. Divide and conquer: a defense of functional localizers. NeuroImage 30 (4), 1088-1096. http://dx.doi.org/10.1016/j. neuroimage.2005.12.062.

Saygin, A.P., McCullough, S., Alac, M., Emmorey, K., 2009. Modulation of BOLD response in motion-sensitive lateral temporal cortex by real and fictive motion sentences. J. Cogn. Neurosci. 22 (11), 2480-2490. http://dx.doi.org/10.1162/ jocn.2009.21388.

Schuil, K.D.I., Smits, M., Zwaan, R.A., 2013. Sentential context modulates the involvement of the motor cortex in action language processing: an FMRI study. Front. Hum. Neurosci. 7, 100. http://dx.doi.org/10.3389/fnhum.2013.00100.

Tettamanti, M., Buccino, G., Saccuman, M.C., Gallese, V., Danna, M., Scifo, P., Perani, D., 2005. Listening to action-related sentences activates fronto-parietal motor circuits. J. Cogn. Neurosci. 17 (2), 273-281. http://dx.doi.org/10.1162/ 0898929053124965.

Van Berkum, J.J.A., De Goede, D., Van Alphen, P.M., Mulder, E.R., Kerstholt, J.H., 2013 How robust is the language architecture? The case of mood. Front. Psychol. 4 505. http://dx.doi.org/10.3389/fpsyg.2013.00505.

van Dam, W.O, van Dijk, M., Bekkering, H., Rueschemeyer, S.-A, 2012. Flexibility in embodied lexical-semantic representations. Hum. Brain Mapp. 33 (10), 2322-2333. http://dx.doi.org/10.1002/hbm.21365.

Willems, R.M., Casasanto, D., 2011. Flexibility in embodied language understanding Front. Psychol. 2, 116. http://dx.doi.org/10.3389/fpsyg.2011.00116.

Willems, R.M., Francken, J.C., 2012. Embodied cognition: taking the next step. Front Psychol. 3, 582. http://dx.doi.org/10.3389/fpsyg.2012.00582.

Willems, R.M., Hagoort, P., Casasanto, D., 2010a. Body-specific representations of action verbs neural evidence from right- and left-handers. Psychol. Sci. 21 (1) 67-74. http://dx.doi.org/10.1177/0956797609354072.

Willems, R.M., Toni, I., Hagoort, P., Casasanto, D., 2010b. Neural dissociations between action verb understanding and motor imagery. J. Cogn. Neurosci. 22 (10), 2387-2400. http://dx.doi.org/10.1162/jocn.2009.21386.

Wilson, A.D., Golonka, S., 2013. Embodied cognition is not what you think it is. Front. Psychol. 4, 58. http://dx.doi.org/10.3389/fpsyg.2013.00058. 